\title{
Postprandial zinc stable isotope response in human blood serum
}

\author{
KAJ SUllivan ${ }^{1,2 *}$, ReBeKaH E. T. MOORE ${ }^{2}$, MARK \\ REHKÄMPER $^{2}$, DANIEL LAYTON-MATTHEWS ${ }^{1}$, \\ MATTHEW I. LEYBOURNE ${ }^{1,3}$, JOHN PUXTY ${ }^{4,5}$, T. KURT \\ KYSER $^{1}$ \\ ${ }^{1}$ Department of Geological Sciences and Geological \\ Engineering, Queen's University, Canada \\ (kajvsullivan@gmail.com) \\ ${ }^{2}$ Department of Earth Science \& Engineering, Imperial \\ College London, United Kingdom \\ ${ }^{3}$ McDonald Institute, Queen's University, Canada \\ ${ }^{4}$ Centre for Studies in Aging and Health, Providence Care \\ Hospital, Canada \\ ${ }^{5}$ Department of Medicine, Queen's University, Canada
}

In recent years, considerable advances have been made in the field of medical isotope metallomics, but there are numerous fundamental physiological processes that remain to be investigated. Past studies report that blood serum $\mathrm{Zn}$ concentrations decrease by $\sim 20 \%$, depending on the size of meal, approximately 3 hours postprandially (i.e. after eating), before gradually returning to baseline values if no meals are consumed over the following 4 to 5 hours $[1,2]$. Nine participants were recruited for this study to investigate whether this postprandial $\mathrm{Zn}$ concentration decrease is accompanied by a $\mathrm{Zn}$ stable isotope response. A baseline serum sample was collected from participants upon arrival in the morning after overnight fasting. A $575.6 \mathrm{kcal}$ meal was then provided and additional serum samples were taken 90 and 180 minutes post-meal to coincide with the peak postprandial response [1]. Serum $\mathrm{Zn}$ concentrations decreased postprandially by an average of $20.9 \pm 8.9 \% 1 \mathrm{SD}$, but this was not accompanied by a $\mathrm{Zn}$ stable isotope response (mean $\Delta^{66} \mathrm{Zn}_{180 \text {-minute - Baseline }}=0.01 \pm 0.05 \%$ 1SD). We propose that this lack of response is due to the rapid, efficient postprandial transfer of albumin-bound $\mathrm{Zn}$ in serum to the liver and pancreas to participate in phosphorylation reactions and the synthesis of digestive enzymes, respectively. These results indicate that studies examining solely the distribution of $\mathrm{Zn}$ isotopes in serum may draw blood samples without considering the timing of the most recent meal. However, future studies that seek to compare serum $\mathrm{Zn}$ concentrations with $\delta^{66} \mathrm{Zn}$ values should draw blood samples in the morning after overnight fasting.

[1] Lowe et al. (1998) British Journal of Nutrition, 80, 363 370. [2] Hambidge et al. (1989) Journal of trace elements and electrolytes in health and disease, 3, 55-57. 